\title{
First trimester maternal tobacco smoking habits and fetal growth
}

\author{
Nanda Prabhu, ${ }^{1}$ Norman Smith, ${ }^{2}$ Doris Campbell, ${ }^{2}$ Leone C Craig, ${ }^{3}$ Anthony Seaton, ${ }^{3}$ \\ Peter J Helms, ${ }^{1}$ Graham Devereux, ${ }^{3}$ Stephen W Turner ${ }^{1}$
}

- Supplementary figures/ tables/appendix are published online only at http://journal.bmj. com/content/vol65/issue3

${ }^{1}$ Academic Child Health, University of Aberdeen, Aberdeen, UK

20bstetrics and Gynaecology, University of Aberdeen, Aberdeen, UK

${ }^{3}$ Environmental and Occupational Medicine, University of Aberdeen, Aberdeen, UK

\section{Correspondence to}

Dr S Turner, Department of Child Health, University of Aberdeen, Royal Aberdeen Children's Hospital, Foresterhill, Aberdeen AB25 2ZG, UK;

s.w.turner@abdn.ac.uk

Received 9 July 2009 Accepted 21 November 2009

\section{ABSTRACT}

Rationale Maternal smoking in pregnancy is associated with reduced birth weight and childhood lung function. This study determined when maternal smoking first influences fetal growth and how this relates to childhood respiratory outcomes.

Methods A longitudinal cohort of 1924 pregnant women was recruited. Fetal ultrasound measurements at 11 weeks (crown-rump length, CRL) and at 20 weeks gestation (femur length, FL, and biparietal diameter, BPD) and birth measurements were recorded. Childhood respiratory symptoms and spirometry were ascertained. Results Of the 1924 original study participants, fetal size was determined in 903 in the first trimester, 1544 in the second trimester and at term in 1737 infants. Maternal smoking when first pregnant was reported in 593 (31\%) and was not associated with reduced CRL. There was an inverse exposure-response relationship between cigarette consumption and FL (mean reduction in lowest compared with highest tertile $0.91 \mathrm{~cm}, p=0.033$ ). Birth weight and length of those born to mothers who did $(n=331)$ and did not $(n=56)$ reduce cigarette consumption were similar and reduced compared with 186 infants whose mothers quit during the first trimester ( $p \leq 0.020)$. Children of mothers who continued smoking had increased wheeze at age 2 years (OR 1.58, $p=0.017$ ) and GP visits with wheeze at age 5 years (OR 2.18, $p=0.030$ ) and mean reduction in forced expiratory volume in $1 \mathrm{~s}$ of $62 \mathrm{ml}(\mathrm{p}=0.014)$ compared with controls.

Conclusions Maternal smoking is associated with reduced fetal measurements in the second and third trimesters but not in the first trimester. Mothers who do not quit smoking during the first trimester deliver smaller infants who go on to have adverse respiratory outcomes in childhood.

\section{INTRODUCTION}

Reduced birth weight is a consequence of an adverse in utero environment and is associated with increased respiratory symptoms and reduced lung function. ${ }^{12}$ An insult to the fetus that results in reduced birth weight may also have implications for fetal lung development where airways are mostly developed by the second trimester and alveolar development commences during the third trimester. ${ }^{3}$

Birth weight is reduced in association with maternal smoking during pregnancy, ${ }^{4} 5$ and this suggests that maternal tobacco smoking is a potentially modifiable factor important in fetal growth failure and later respiratory disease. Evidence that maternal smoking causes fetal growth retardation is provided by a meta-analysis of studies where smoking cessation advice was given to pregnant mothers. ${ }^{6}$

While the relevance of maternal smoking to fetal growth $^{4} 5$ and infant lung function ${ }^{7}$ is widely accepted, some clinically relevant questions remain unanswered. Knowledge of the gestational age at which fetal growth failure begins-and, by inference, the onset of abnormal lung development-is not known but is relevant when deciding when smoking interventions should be introduced before or after pregnancy is recognised. One study reported reduced fetal size in the second trimester in association with maternal smoking, ${ }^{8}$ and smoking only in the first trimester has been associated with normal birth weight ${ }^{9}$; together these findings suggest that exposure in the first trimester might not influence fetal size. A second area of uncertainty is whether reduced smoking during pregnancy might attenuate fetal growth retardation. ${ }^{10} 11$

In a birth cohort recruited by our group we have obtained fetal measurements in the first and second trimesters and have related these to maternal smoking status and childhood respiratory outcomes. Our first hypothesis is that maternal smoking is not associated with reduced fetal size in the first trimester. Our second hypothesis is that maternal smoking cessation, but not reduced maternal daily cigarette consumption, is associated with normal fetal size at birth. Finally, we tested the hypothesis that maternal smoking cessation during pregnancy is associated with respiratory outcomes similar to those for children of non-smoking mothers.

\section{METHODS}

\section{Study design}

Mothers attending a first trimester 'dating' ultrasound scan were invited to participate in a cohort study designed to relate antenatal dietary exposures to childhood asthma and allergy. Recruitment was non-consecutive. The non-participation rate was $26 \%{ }^{12}$ and there was no selection for maternal atopy or asthma. At enrolment, maternal smoking status at the beginning of pregnancy and the number of cigarettes smoked per day were ascertained using a researcher-administered questionnaire. Fetal measurements were recorded in the first and second trimester scan. At 32 weeks gestation the mother's smoking status was reassessed by questionnaire. At birth the infant's weight, length and head circumference were recorded. Respiratory symptoms were determined by questionnaire at ages 2 and 5 years. Spirometry was measured at age 5 years. This study was approved by the local research ethics 
committee, written parental consent was obtained as was verbal assent from children.

\section{Smoking categories}

At enrolment, mothers were categorised as non-smoker or current smoker. Mothers were then also categorised as never smoked, ex-smoker (ie, smoker but not when first pregnant), quit smoking in the first trimester since becoming pregnant, reduced cigarette consumption during the first trimester and no change in cigarette consumption during the first trimester. Paternal smoking status (current or non-current) was verified by questionnaire when the infant was aged 6 months.

\section{Fetal measurements}

Scans took place between July 1997 and October 1999 and were retrieved retrospectively in 2007. Scans in the first and second trimester included assessments completed between 8 and 12 weeks or 18 and 22 weeks gestation, respectively. The crown-rump length (CRL) was measured at the first trimester scan and femur length (FL) and biparietal diameter (BPD, innerouter) were measured at the second trimester scan. The CRL is defined as the longest length measured between the crown of the head and the buttocks, ${ }^{13}$ the FL is the distance between the proximal and distal femoral diaphyses/growth plates ${ }^{14}$ and the $\mathrm{BPD}$ is the measurement made from a midline/sagittal cranial image. ${ }^{15}$ An ATL (Ultramark 4A) or Toshiba (SSA-240A or SSA$340 \mathrm{~A})$ ultrasound scanner was used to determine fetal measurements and calibrated in accordance with the manufacturer's recommendations. Mothers were asked whether the date of their last menstrual period (LMP) was certain, approximate or uncertain. Gestation was ascertained either by date of LMP for mothers with a regular 28-day menstrual cycle or CRL at booking scan. Gestation predicted by CRL was adopted in cases where the gestation from LMP and CRL differed by more than 7 days.

\section{Spirometry}

Spirometry was measured with a pneumotachograph with incentive display software (Spirotrac IV version 4.22, Vitalograph, Bucks, UK). The quality control for spirometry measurements is described elsewhere. ${ }^{16}$

\section{Statistical analysis}

The $\chi^{2}$ and Student $t$ tests were used to compare differences between groups. Multivariate linear regression models were created to explore the relationship between fetal and neonatal measurements and maternal smoking status in the first trimester adjusting for factors likely or known to influence fetal size including: gestation when the measurement was made, sex, ${ }^{17}$ father currently smoking, maternal height, maternal alcohol intake during pregnancy (g/day), maternal plasma $\boldsymbol{\alpha}$-tocopherol (adjusted for cholesterol) at enrolment and the 2006 Scottish Index of Multiple Deprivation (SIMD, see online supplement for details). The results were presented as the mean difference between groups and 95\% CIs. Additionally, the quadratic models used in a previous study were used for the analysis of BPD and FL. ${ }^{8}$ Repeated measures analysis of variance (see online supplement for advantages offered by this approach) was used to study changes in $\mathrm{z}$ scores of fetal measurements using published equations (CRL, ${ }^{13} \mathrm{FL}^{14}{ }^{14} \mathrm{BPD},{ }^{15}$ birth length, weight and head circumference $\left.{ }^{18}\right)$ in the context of maternal smoking status, adjusting for the factors included in the linear regression models. Logistic and linear regression models were created to relate childhood outcomes to maternal smoking habit during pregnancy while adjusting for relevant factors (see online supple- ment). Owing to attrition in numbers, children whose mothers reduced or did not change smoking during pregnancy were considered as a single group. Significance was assumed at the $5 \%$ level and a standard statistical package was used (SPSS Version 17.0.0).

\section{RESULTS \\ Study subjects}

Two thousand mothers were recruited and there were 1924 live born singleton infants. First trimester fetal measurements were available for 903 individuals. BPD measurements were available in 1560 fetuses and FL in 1544. At birth, weight was recorded for 1841 infants, crown-heel length in 1737 and head circumference in 1740. Table 1 compares details of the 790 children for whom CRL, BPD and birth weight measurements were and were not complete. The date of LMP was certain in 1227, approximate in 550 and uncertain in two mothers; LMP accuracy was not determined in 221 mothers. At the first trimester assessment (median gestation 11 weeks) there were 593 mothers smoking when first pregnant and 1406 non-smokers (including 329 exsmokers). Of the 593 smokers, 59 mothers had not reduced cigarette consumption since becoming pregnant, 331 reported reduced cigarette consumption and 203 mothers had quit smoking by the first trimester assessment. No mother reported having started smoking or increasing cigarette consumption since becoming pregnant.

\section{Factors associated with maternal smoking status}

There were differences across five maternal smoking groups for age at starting smoking $(p<0.001)$, SIMD $(p<0.001)$ and number of cigarettes smoked in the first $(p<0.001)$ and third trimester $(p=0.047)$ (table 2). There was no difference in the daily alcohol intake for mothers who smoked in the first trimester (see online supplement). The median number of cigarettes smoked per day in the first trimester was 15 (IOR 10-20). In the third trimester 1377 questionnaires were returned; the median number of cigarettes smoked daily was 10 (IOR 7-15) and 229 mothers (17\%) currently smoked, 182 of whom had reduced cigarette consumption in the first trimester, 30 had not changed cigarette consumption since becoming pregnant and 17 had previously quit in the first trimester (data from these 17 were removed from the analysis).

\section{First and second trimester fetal measurements and maternal smoking}

There was no difference in CRL between fetuses whose mothers did and did not smoke and this remained the case when only

Table 1 Comparison of individuals whose fetal crown-rump length, biparietal diameter and birth weight were and were not all determined

\begin{tabular}{lcl}
\hline & $\begin{array}{l}\text { All measurements } \\
\text { available (n=790 } \\
\text { unless stated) }\end{array}$ & $\begin{array}{l}\text { All measurements } \\
\text { not available } \\
\text { (n=1210 unless stated) }\end{array}$ \\
\hline Male sex & $53 \%(411 / 782)$ & $49 \%(536 / 1096)$ \\
Maternal smoker in first trimester & $28 \%(218)$ & $31 \%(375)$ \\
Median number of cigarettes smoked & $15(10-20)$ & $15(10-20)$ \\
Mother quit after first trimester & $11 \%(89)$ & $9 \%(114)$ \\
Father smoker & $23 \%(127 / 560)$ & $23 \%(184 / 817)$ \\
Mean (SD) maternal height $(m)$ & $1.63(0.06)$ & $1.63(0.06)$ \\
Mean (SD) maternal plasma & $9.7(2.8)$ & $10.3(3.0)$ \\
$\alpha$-tocopherol ( $\mu \mathrm{g} / \mathrm{ml})$ & $\mathrm{n}=788$ & $\mathrm{n}=1202$ \\
Median (range) SIMD quintile & $4(1-5)$ & $4(1-5)$ \\
\hline
\end{tabular}

No differences were seen between the groups.

SIMD, Scottish Index for Multiple Deprivation. 
Table 2 Comparison of maternal characteristics across the five smoking groups

\begin{tabular}{|c|c|c|c|c|c|c|}
\hline & Never smoked & Ex-smoker & $\begin{array}{l}\text { Quit in first } \\
\text { trimester }\end{array}$ & $\begin{array}{l}\text { Reduced cigarette } \\
\text { consumption }\end{array}$ & $\begin{array}{l}\text { No reduction in } \\
\text { cigarette consumption }\end{array}$ & p Value \\
\hline Mean (SD) maternal height (cm) & $163.2(6.5) n=1076$ & $163.8(6.1) n=346$ & $162.9(6.0) n=186$ & $162.5(5.8) n=331$ & $162.4(6.4) n=59$ & $0.055^{*}$ \\
\hline Mean (SD) age started smoking (years) & & $16.4(2.6) \mathrm{n}=345$ & $15.9(2.7) \mathrm{n}=189$ & $14.9(2.5) \mathrm{n}=331$ & $14.5(2.4) n=59$ & $<0.001^{*}$ \\
\hline Median (range) SIMD quintile & $4(1-5) n=1070$ & $4(1-5) n=344$ & $4(1-5) n=184$ & $3(1-5) n=328$ & $2(1-5) n=59$ & $<0.001 \dagger$ \\
\hline $\begin{array}{l}\text { Median (range) daily cigarettes when } \\
\text { first pregnant }\end{array}$ & 0 & 0 & $10(1-30) n=185$ & $20(1-60) n=330$ & $20(1-40) n=59$ & $<0.001 \dagger$ \\
\hline $\begin{array}{l}\text { Median (range) daily cigarettes in third } \\
\text { trimester }\end{array}$ & 0 & 0 & 0 & $10(1-20) n=182$ & $12(3-30) n=30$ & $0.047 \neq$ \\
\hline$\%$ With partner who smokes & $9 \%(93 / 1077)$ & $88 \%(43 / 49)$ & $76 \%(38 / 50)$ & $67 \%(114 / 196)$ & $72 \%(23 / 32)$ & $<0.001 \S$ \\
\hline
\end{tabular}

Trend tests were as follows:

*ANOVA (with Bonferroni correction).

†Kruskal-Wallis test (comparison between three groups).

$\neq$ Mann-Whitney test.

$\S \chi^{2}$ test.

SIMD, Scottish Index of Multiple Deprivation.

those pregnancies where date of LMP was certain were considered (see online supplement). Applying both the linear and quadratic models, ${ }^{8}$ there were no differences in BPD and FL between fetuses whose mothers did and did not smoke when first pregnant (results presented in the online supplement). There was an exposure-dependent reduction in FL among exposed fetuses (figure 1), mean FL in fetuses in the highest tertile for daily maternal cigarette consumption (12-30 cigarettes per day) being $0.91 \mathrm{~cm}$ shorter $(95 \%$ CI 0.07 to 1.75$)$ than those in the lowest tertile ( $1-8$ cigarettes per day), $p=0.033$. There was no relationship between tertile of exposure and BPD.

\section{Measurements at birth and maternal smoking}

Compared with unexposed fetuses, fetuses whose mothers smoked when first pregnant had lower birth weight (mean reduction $166 \mathrm{~g}(95 \%$ CI 94 to 237) $\mathrm{p}<0.001)$, shorter crown-heel length (mean reduction $0.67 \mathrm{~cm}(95 \%$ CI 0.36 to $0.97, \mathrm{p}<0.001)$ and smaller occipitofrontal circumference (mean reduction $0.36 \mathrm{~cm}$ (95\% CI 0.14 to 0.58$), \mathrm{p}=0.001)$. There was no relationship between birth weight, length or head circumference and tertile of maternal daily cigarette consumption in either the

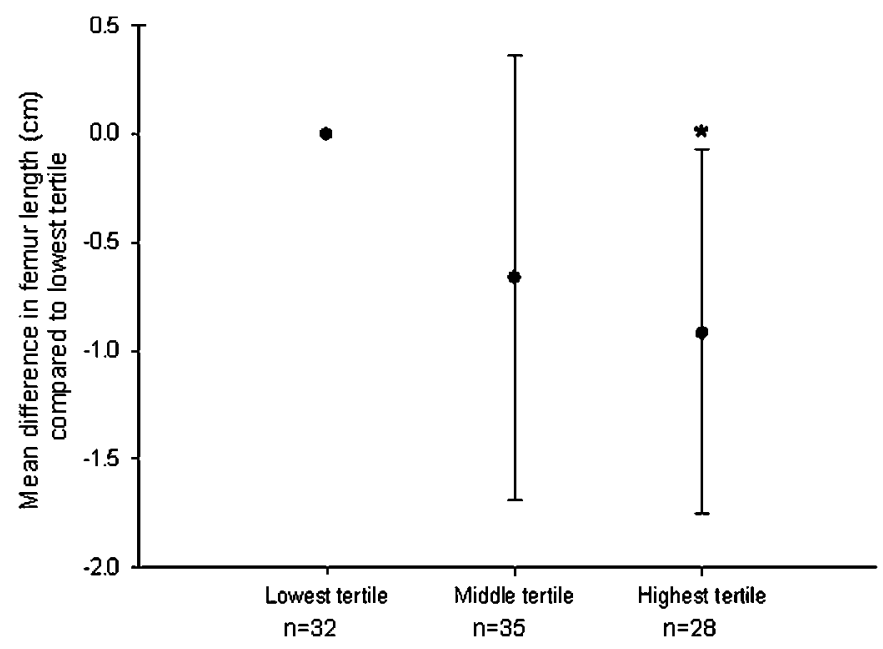

Figure 1 Mean differences in femur length $(\mathrm{cm})$ and $95 \% \mathrm{Cl}$ between 20-week-old fetuses grouped by tertile of maternal daily cigarette consumption when first pregnant. The range of daily cigarette consumption was $1-8$ for the lowest, $9-12$ for the middle and 12-30 for the highest tertile. Analysis adjusted for sex, gestation at scan, paternal smoking, Scottish Index of Multiple Deprivation, maternal height and maternal plasma $\alpha$-tocopherol and cholesterol levels. ${ }^{*} p=0.033$ compared with lowest tertile. first or third trimester. Compared with the group who continued smoking during the first trimester, birth weight $(p=0.012)$ and length $(p=0.020)$ but not head circumference were greater in infants whose mothers quit after becoming pregnant (table 3 ). There were no differences between infants whose mothers reduced and continued smoking (table 3 ).

\section{Fetal growth trajectory and maternal smoking: longitudinal analysis}

Complete fetal scan and birth measurements were available in 760 infants where maternal smoking was also determined in the first trimester. In the longitudinal analysis of CRL, FL and birth weight, unchanged maternal smoking was associated with mean reductions in FL of 0.64 z scores (95\% CI 0.08 to 1.21) and birth weight of 0.61 z scores (95\% CI 0.11 to 1.11) (figure 2), reduced maternal smoking was associated with a mean reduction in birth weight of 0.56 z scores (95\% CI 0.67 to 0.75 ) (figure 3) and quitting was associated with normal FL and birth weight (figure 4). The results of the longitudinal analyses including CRL, BPD and head circumference and CRL, FL and crown-rump length are shown in the online supplement.

\section{Relationship between maternal smoking habit and childhood respiratory outcomes}

Questionnaire data were available in 1374 children at age 2 years and in 1253 children aged 5 years. Reliable spirometry was obtained in 594 children. Table 4 shows that children whose mothers continued to smoke during pregnancy had increased respiratory symptoms and reduced lung function compared with children born to non-smokers; children whose mothers quit after the first trimester were at increased risk for asthma at age 2 years but had normal lung function.

\section{DISCUSSION}

The aims of this observational study were to relate maternal smoking during pregnancy to fetal growth and childhood respiratory outcomes. The first novel finding was that fetal size in the first trimester was apparently unaffected by maternal smoking, while there was an exposure-response relationship between cigarettes smoked and fetal FL in the second trimester. We also report associations between persistent maternal smoking throughout pregnancy and increased childhood respiratory symptoms and reduced lung function. Given that many pregnancies are unplanned, mothers can be encouraged to stop smoking in the first trimester after becoming pregnant in the expectation of delivering infants of normal size with no increased risk for respiratory illnesses at age 5 years. 
Table 3 Mean differences and 95\% Cls between anthropometric measurements at birth in infants whose mothers quit or reduced smoking compared with infants whose mothers did not change their cigarette consumption after the first trimester

\begin{tabular}{|c|c|c|c|c|}
\hline & $\begin{array}{l}\text { No change in cigarette } \\
\text { consumption }(n=24)\end{array}$ & $\begin{array}{l}\text { Reduced cigarette } \\
\text { consumption }(n=145)\end{array}$ & $\begin{array}{l}\text { Quit after first } \\
\text { trimester }(n=50)\end{array}$ & $\begin{array}{l}\text { Non-smoker } \\
(\mathrm{n}=927)\end{array}$ \\
\hline Mean difference in birth weight $(\mathrm{g})$ & 0 & $104(-73$ to 282$), p=0.250$ & 246 (46 to 445 ), $p=0.012$ & 290 (115 to 463$), p=0.001$ \\
\hline $\begin{array}{l}\text { Mean difference in crown-heel } \\
\text { length }(\mathrm{cm})\end{array}$ & 0 & $0.65(-0.11$ to 1.40$), p=0.092$ & $1.14(0.29$ to 1.99$), p=0.020$ & 1.37 (0.63 to 2.11), $\mathrm{p}<0.001$ \\
\hline $\begin{array}{l}\text { Mean difference in occipitofrontal } \\
\text { circumference }(\mathrm{cm})\end{array}$ & 0 & $0.08(-0.42$ to 0.58$), p=0.746$ & $0.39(-0.17$ to 0.95$), p=0.170$ & $0.44(-0.52$ to 0.92$), p=0.080$ \\
\hline
\end{tabular}

Analysis adjusted for sex, maternal height, maternal plasma $\alpha$-tocopherol, maternal plasma cholesterol, paternal smoking, gestation at birth and Scottish Index of Multiple Deprivation.

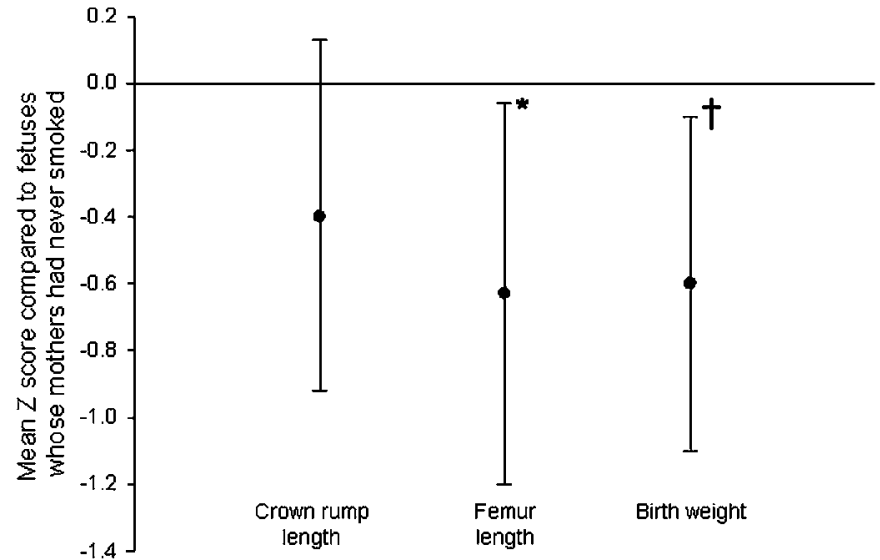

Figure 2 Fetal measurements at 11 and 20 weeks and at term for the 13 infants born to mothers whose cigarette consumption was unchanged during the first trimester compared with the 435 fetuses whose mothers never smoked. ${ }^{*} \mathrm{p}=0.029,+\mathrm{p}=0.019$.

Until recently, the evidence in the literature suggested that maternal smoking did not influence fetal growth until the third trimester of pregnancy ${ }^{17}{ }^{19-21}$; however, a study of 7000 pregnancies has reported reduced FL but not head circumference in the second trimester. ${ }^{8}$ It is possible that earlier studies which found no association between maternal smoking and reduced FL in the second trimester ${ }^{17} 1920$ were underpowered. The results of the present study are in accord with studies that have reported normal birth weight in infants born to mothers who quit smoking in early pregnancy. 922

The results of the present study are also consistent with a previous report from this cohort where exposure to products of tobacco smoke was associated with increased wheeze at 2 years of age. ${ }^{23}$ The relationship between maternal smoking during pregnancy and respiratory outcomes is complex since antenatal exposure is usually followed by postnatal exposure. The associations between antenatal exposure and postnatal outcomes presented here (table 1) are independent of postnatal exposure; this finding is consistent with at least one other study ${ }^{24}$ and suggests that antenatal exposure may be more harmful than postnatal exposure.

The absence of a relationship between maternal smoking per se and fetal measurements in the second trimester is most likely explained by combining all mothers who smoked. Further analysis showed that FL was not reduced in those whose mothers quit within the first trimester (figure 4). The exposureresponse relationship between maternal smoking and FL confirms that exposure is related to reduced fetal growth and suggests that the relationship is causative. The Generation $\mathrm{R}$ study found an association between FL and the lowest and highest smoking groups but not the intermediate group of

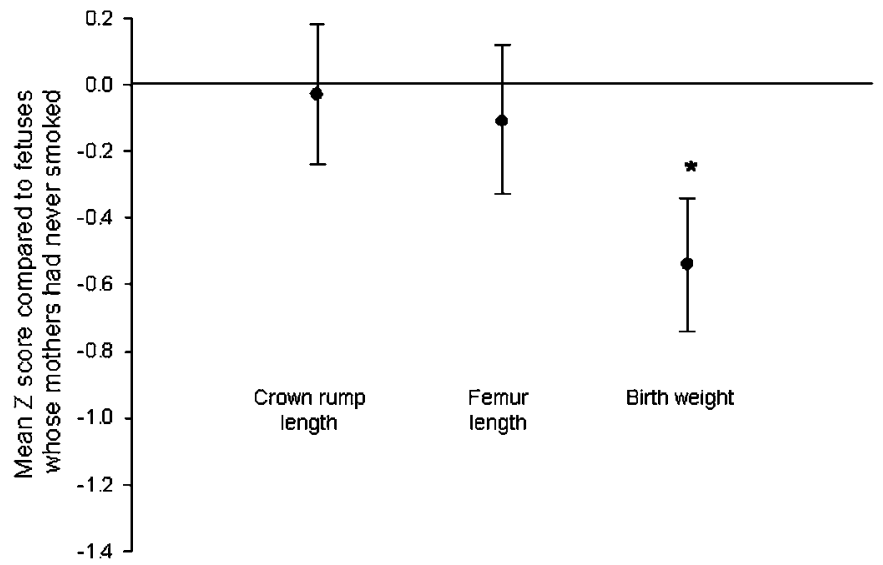

Figure 3 Fetal measurements at 11 and 20 weeks and at term for the 110 infants born to mothers whose cigarette consumption was reduced during the first trimester compared with the 435 fetuses whose mothers never smoked. ${ }^{*} \mathrm{p}<0.001$.

smokers. ${ }^{8}$ The authors noted that this apparently inconsistent finding may have been by chance and suggested that further studies should assess exposure-response trends for fetal growth; here we confirm a linear dose-response relationship between exposure and second trimester femur growth.

CRL is used to determine gestation in many individuals and a negative effect of maternal smoking on fetal size may have been missed since (smaller) exposed fetuses could have been considered non-exposed less mature fetuses. We considered this and found no association between maternal smoking and CRL among mothers where the LMP was certain and gestation was not included in the model. While a reduction in CRL due to

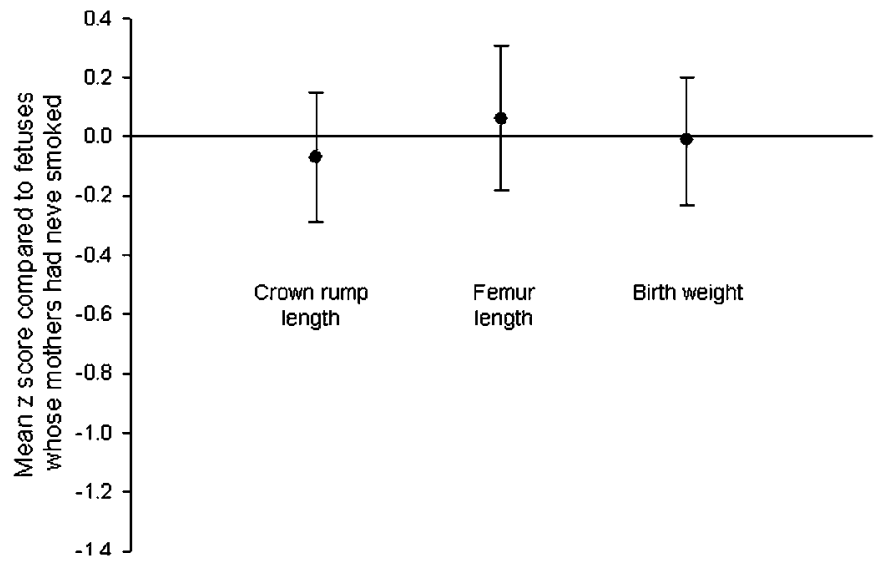

Figure 4 Fetal measurements at 11 and 20 weeks and at term for the 84 infants born to mothers who stopped smoking during the first trimester compared with the 345 fetuses whose mothers never smoked. 
Table 4 Respiratory outcomes at ages 2 and 5 years in groups categorised by maternal smoking during pregnancy and referenced to children whose mothers had never smoked

\begin{tabular}{|c|c|c|c|c|}
\hline & $\begin{array}{l}\text { Smoking throughout } \\
\text { pregnancy }\end{array}$ & Quit after first trimester & Ex-smoker & $\begin{array}{l}\text { Never } \\
\text { smoked }\end{array}$ \\
\hline $\begin{array}{l}\text { OR for diagnosed asthma aged } 2 \text { years } \\
(95 \% \mathrm{Cl})(\mathrm{n}=55)^{*}\end{array}$ & 2.09 (0.80 to 5.51$), \mathrm{p}=0.135$ & 3.40 (1.52 to 7.63 ), $\mathrm{p}=0.003$ & $1.26(0.57$ to 2.80$), p=0.566$ & 1 \\
\hline $\begin{array}{l}\text { OR for diagnosed asthma aged } 5 \text { years } \\
(95 \% \mathrm{Cl})(\mathrm{n}=116)^{*}\end{array}$ & $1.27(0.63$ to 2.56$), p=0.507$ & 1.26 (0.63 to 2.51 ), $\mathrm{p}=0.525$ & $0.58(0.31$ to 1.09$), p=0.090$ & 1 \\
\hline $\begin{array}{l}\text { Mean difference in FVC aged } 5 \text { years }(\mathrm{ml}) \\
(\mathrm{n}=589) \dagger\end{array}$ & $-53(0$ to -107$), p=0.051$ & $-12(+47$ to -72$), p=0.681$ & $-15(+49$ to -79$), p=0.647$ & 0 \\
\hline $\begin{array}{l}\text { Mean difference in } \mathrm{FEV}_{1} \text { aged } 5 \text { years }(\mathrm{ml}) \\
(\mathrm{n}=445) \dagger\end{array}$ & $-62(12$ to 112$), p=0.014$ & $-18(+37$ to -73$), p=0.525$ & $-57(+2$ to -116$), p=0.056$ & 0 \\
\hline
\end{tabular}

*Model adjusted for sex, maternal asthma, current smoke exposure, Scottish Index of Multiple Deprivation, treatment with antibiotics in the first 6 months, breast feeding and maternal intake of vitamin $C, D$ and $E$.

†Model adjusted for sex, height, maternal height, maternal asthma, current smoke exposure and maternal plasma $\alpha$-tocopherol and cholesterol at enrolment.

$\mathrm{FEV}_{1}$, forced expiratory volume in $1 \mathrm{~s}$; FVC, forced vital capacity.

exposure might potentially have been missed, first trimester fetal size is highly predictive of gestation ${ }^{13}$ and this suggests that maternal smoking does not substantially influence early fetal growth.

Although many mothers who were smoking at conception reduced their cigarette consumption from 20 to 10 cigarettes per day, this had no apparent benefit to the fetus although there was a trend which approached significance for increased birth length (table 4). Ours is the first study to describe non-significant trends for increased birth length in association with reduced cigarette consumption, and others have described similar trends for birth weight. ${ }^{10} 11$ Larger studies might be able to detect associations between reduced maternal smoking and significantly smaller decrements in fetal size at birth, but the magnitude of the benefit is likely to be relatively small.

The mechanisms that explain the association between exposure to products of tobacco smoke and fetal growth failure are not fully understood. Carbon monoxide, a by-product of tobacco smoking, induces fetal hypoxia ${ }^{25}$ which may directly induce fetal growth failure. Products of tobacco smoke can indirectly affect fetal growth via a negative influence on placental function ${ }^{26}$; for example, nicotine causes vasoconstriction in placental vessels. ${ }^{26}$ Maternal smoking may also reduce fetal growth by suppression of placental growth hormone and fetal insulin-like growth factor endocrine function. ${ }^{27}$ Given the many constituents of tobacco smoke, it is plausible that there is more than one mechanism for the associated fetal growth retardation.

A number of factors should be considered when interpreting these results. One limitation is that first trimester scans could not be retrospectively identified in half of the study population, but we have shown that the absence of fetal data was not associated with maternal smoking status and thus is unlikely to have substantially affected the results (table 1). Second, the subgroups in the longitudinal analysis were relatively small (in particular the unchanged cigarette consumption group), but the results of the longitudinal study were consistent with the crosssectional analyses. A further limitation was that we were not able to relate maternal smoking to fetal thoracic circumference which might be more closely related to fetal lung size. Sitting height and limb length are accurate predictors of lung function in children $^{28} 29$ and are very similar dimensions to CRL and FL, respectively, so we believe that the fetal measurements made are relevant to fetal lung size. Fourth, we were not able to replicate the dose-response relationship for reported maternal smoking and birth size demonstrated in some $e^{103031}$ but not all ${ }^{4}$ studies. There is evidence of under-reporting of smoking by pregnant mothers, ${ }^{32}$ and this may have affected our analysis. Had we included an objective measure of maternal cigarette consumption such as urinary cotinine, we may have been able to confirm other reports of a dose-response relationship at relatively low consumptions. A further limitation is that we inferred paternal smoking status during pregnancy from data collected when the infant was aged 6 months; however, father's smoking status might be expected to remain constant before and after the infant's birth.

In summary, we have described the relationship between maternal smoking in the first trimester and fetal growth. Our findings demonstrate the importance of smoking cessation after mothers find themselves pregnant. Engaging pregnant mothers in smoking cessation is feasible, although not necessarily successful, ${ }^{33}$ but should still be encouraged during the first trimester

Funding Asthma UK and Tenovus Scotland

Competing interests None.

Ethics approval This study was conducted with the approval of the North of Scotland Research ethics committee.

Provenance and peer review Not commissioned; externally peer reviewed.

\section{REFERENCES}

1. Barker DJ, Godfrey KM, Fall C, et al. Relation of birth weight and childhood respiratory infection to adult lung function and death from chronic obstructive airways disease. BMJ (Clin Res Ed) 1991;303:671-5.

2. Canoy D, Pekkanen J, Elliott $P$, et al. Early growth and adult respiratory function in men and women followed from the fetal period to adulthood. Thorax 2007:62:396-402

3. Stick S. Pediatric origins of adult lung disease. 1. The contribution of airway development to paediatric and adult lung disease. Thorax 2000;55:587-94.

4. Ellard GA, Johnstone FD, Prescott RJ, et al. Smoking during pregnancy: the dose dependence of birthweight deficits. Br J Obstet Gynaecol 1996;103:806-13.

5. England LJ, Kendrick JS, Gargiullo PM, et al. Measures of maternal tobacco exposure and infant birth weight at term. Am J Epidemiol 2001;153:954-60.

6. Dolan-Mullen P, Ramirez G, Groff JY. A meta-analysis of randomized trials of prenatal smoking cessation interventions. Am J Obstet Gynecol 1994;171:1328-34.

7. Tager IB, Weiss ST, Munoz A, et al. Longitudinal study of the effects of maternal smoking on pulmonary function in children. N Engl J Med 1983;309:699-703.

8. Jaddoe VW, Verburg BO, de Ridder MA, et al. Maternal smoking and fetal growth characteristics in different periods of pregnancy: the generation R study. Am J Epidemiol 2007;165:1207-15.

9. MacArthur C, Knox EG. Smoking in pregnancy: effects of stopping at different stages. Br J Obstet Gynaecol 1988;95:551-5. 
10. England LJ, Kendrick JS, Wilson HG, et al. Effects of smoking reduction during pregnancy on the birth weight of term infants. Am J Epidemiol 2001; 154:694-701.

11. Li C0, Windsor RA, Perkins L, et al. The impact on infant birth weight and gestational age of cotinine-validated smoking reduction during pregnancy. J Am Med Assoc 1991:269:1519-24.

12. Martindale S, McNeill G, Devereux G, et al. Antioxidant intake in pregnancy in relation to wheeze and eczema in the first two years of life. Am J Respir Crit Care Med 2005:171:121-8.

13. Robinson HP, Fleming JE. A critical evaluation of sonar "crown-rump length" measurements. Br J Obstet Gynaecol 1975;82:702-10.

14. Chitty LS, Altman DG, Henderson A, et al. Charts of fetal size: 4. Femur length. $\mathrm{Br} J$ Obstet Gynaecol 1994;101:132-5.

15. Chitty LS, Altman DG, Henderson A, et al. Charts of fetal size: 2. Head measurements. Br J Obstet Gynaecol 1994;101:35-43.

16. Turner SW, Craig LCA, Harbour PJ, et al. Spirometry in 5-year-olds: validation of current guidelines and the relation with asthma. Pediatr Pulmonol 2007:42:1144-51.

17. Zaren B, Lindmark G, Bakketeig L. Maternal smoking affects fetal growth more in the male fetus. Paediatr Perinat Epidemiol 2000;14:118-26.

18. Freeman JV, Cole TJ, Chinn S, et al. Cross sectional stature and weight reference curves for the UK, 1990. Arch Dis Child 1995;73:17-24.

19. Bergsjo P, Bakketeig LS, Lindmark G. Maternal smoking does not affect fetal size as measured in the mid-second trimester. Acta Obstet Gynecol Scand 2007;86:156-60.

20. Bernstein IM, Plociennik K, Stahle S, et al. Impact of maternal cigarette smoking on fetal growth and body composition. Am J Obstet Gynecol 2000;183:883-6.

21. Lampl M, Kuzawa CW, Jeanty P. Prenatal smoke exposure alters growth in limb proportions and head shape in the midgestation human fetus. Am J Human Biol 2003;15:533-46.
22. Jaddoe VW, Troe EJ, Hofman A, et al. Active and passive maternal smoking during pregnancy and the risks of low birthweight and preterm birth: the Generation R Study. Paediatr Perinat Epidemiol 2008;22:162-71.

23. Turner SW, Craig LC, Harbour PJ, et al. Early rattles, purrs and whistles as predictors of later wheeze. Arch Dis Child 2008;93:701-4.

24. Hayatbakhsh MR, Sadasivam S, Mamun AA, et al. Maternal smoking during and after pregnancy and lung function in early adulthood: a prospective study. Thorax 2009;64:810-4.

25. Soothill PW, Morafa W, Ayida GA, et al. Maternal smoking and fetal carboxyhaemoglobin and blood gas levels. Br J Obstet Gynaecol 1996;103:78-82.

26. Shiverick KT, Salafia C. Cigarette smoking and pregnancy I: Ovarian, uterine and placental effects. Placenta 1999:20:265-72.

27. Coutant R, Boux de Casson F, Douay 0, et al. Relationships between placenta $\mathrm{GH}$ concentration and maternal smoking, newborn gender, and maternal leptin: possible implications for birth weight. J Clin Endocrinol Metab 2001:86:4854-9

28. Kivastik J, Kingisepp PH. Lung function in Estonian children: effect of sitting height Clin Physiol 1995;15:287-96.

29. Gauld LM, Kappers J, Carlin JB, et al. Prediction of childhood pulmonary function using ulna length. Am J Respir Crit Care Med 2003:168:804-9.

30. Hebel JR, Fox NL, Sexton M. Dose-response of birth weight to various measures of maternal smoking during pregnancy. J Clin Epidemiol 1988;41:483-9.

31. Secker-Walker RH, Vacek PM, Flynn BS, et al. Estimated gains in birth weight associated with reductions in smoking during pregnancy. J Reprod Med 1998:43:967-74.

32. Klebanoff MA, Levine RJ, Clemens JD, et al. Serum cotinine concentration and self-reported smoking during pregnancy. Am J Epidemiol 1998;148:259-62.

33. Tappin DM, Lumsden MA, Gilmour WH, et al. Randomised controlled trial of home based motivational interviewing by midwives to help pregnant smokers quit or cut down. BMJ (Clin Res Ed) 2005;331:373-7. 